\title{
Applying Nearpod to 11th Grade to Improve Classroom Interactions
}

\author{
Yongfei $\mathrm{Qi}^{1, *, \dagger}{ }^{*}$ Eryu Shen ${ }^{2, *, \dagger}$, Siqi Xue ${ }^{3, *, \dagger}$ \\ ${ }^{1}$ School of Foreign Languages, Minzu University of China, Beijing, 100000, China \\ ${ }^{2}$ School of Humanities and Foreign Languages, China Jiliang University, Hangzhou, Zhejiang,310000, China \\ ${ }^{3}$ Beijing New Oriental Yangzhou Foreign Language School International High School, Yangzhou, Jiangsu,225000, \\ China \\ *Corresponding author. Email: 20143017@stu.nun.edu.cn
}

Those authors contributed equally.

\begin{abstract}
In the Nearpod lesson, we intend to teach our students global warming, which is one of the most popular topics in the field of climate change. The course is designed for 11th-grade students, and it will be given in their science class. During the lesson, students are encouraged to explore the effects of global warming in a way that how it is changing the Earth and our lives. Afterwards, certain materials are provided from which they will learn the 5 main causes of it and explain them in their own words through group work. Moreover, we want our students to develop practical solutions for tackling global warming based on the Drawdown Framework and fight for environmental protection, which we believe should be the end of the lesson. The method used in the study is Classroom Observation, and this research will be qualitative research that takes one class as an example to see how Nearpod can be designed as an interactive tool in class. Through the research, we found that Nearpod provides various perspectives that bring students into Global Warming. The approach to concept map scoring in the study represents a distinct departure from traditional methods that focus on characteristics such as hierarchy and branching and shows the relationships between different kinds of causes and effects in visual. Moreover, we provide a "Web Content" about the 5 main causes for global warming, which students would together discuss with their partners and explain how their assigned topic contributes to global warming as a whole in their own words on the collaborate board, where opinions are exposed and exchanged. Therefore the feedbacks from peers are highly welcome. At last, we use summative assessment to provide evidence for students' achievements.
\end{abstract}

Keywords: Nearpod, Technology, Global Warming, Concept Map, Collaborate Board, Formative Assessment

\section{INTRODUCTION}

With the development of technology, Nearpod has become a significant platform, as one of the many webbased platforms that provide an interactive learning class [1]. Teachers engage students in active learning with various content and activities. As teachers use technologies more often in recent classes, one primary problem with Nearpod is how to engage students in class more effectively. As far as we know, no previous research has investigated how to engage students in active learning about global warming on the Nearpod teaching for 11th-grade students. We, therefore, analyzed teaching methods in Nearpod and investigated whether they worked. We design a class about climate change-- global warming, enhancing students' engagement and promoting active learning through Nearpod with highcognitive demand tasks [2]. The ultimate goal is to see how the designed activities function in the class so that people can use this mode in the later Nearpod lessons.

\section{LITERATURE REVIEW}

\subsection{Nearpod}

In neo classes, it is common to see teachers and students using Nearpod to perform the study. For students, it is creative enough for them to try and figure out various functions of Nearpod. Different functions seem to work in different ways, but they are all helpful 
for students. In detail, students need to search online to review the theme and have some basic knowledge about it. Then, during the class, teachers use Nearpod to show them more specific details about the theme. They could use web content, pictures or even videos to bring students into the theme. Then, they were divided into groups to complete the final project. Since they can search and collect information freely online, they must have different ingenious ideas. They can exchange their ideas in groups, and members in groups all have equal opportunities to do their best [3]. Before the class, they need to do some matching pairs and quiz to evaluate their acceptance of the class. All the tests were in different levels and had two forms for students. It could provide a comprehensive evaluation for teachers to consult.

For teachers, Nearpod could provide a broader background for students to review instead of just reading some papers. It is boring for students to just listen to a teacher talk on the stage. Using Nearpod, instead, could kindle their interests because teachers could use it to show students pictures, videos or even play some games on it. Additionally, Nearpod uses summative assessment to provide evidence for students' achievements [4]. Teachers do not need to just use paper tests to evaluate students' acceptance of the class. Nearpod provides accurate test results for teachers.

\subsection{Concept Map}

Kinchin and David hold the view that concept maps help teachers focus teaching for more effective learning and may be used as a basis for structuring groups in collaborative settings [5]. The concept map is also a useful and meaningful tool that helps students integrate new information and build upon the existing concepts and knowledge. Students construct and reconstruct knowledge in the concept maps, leading to meaningful learning. Concept maps help students recognize previous materials and new cognitions by showing the relevant connections. It can also make an overall framework of the concept explicitly. Therefore, students can display a fragmentary understanding of the topic and then compose an overview thinking of the topic.

Concept maps can encourage the participation of collaborative groups by reducing the burden on working memory [6]. Students need to communicate with each other, exchange their ideas and collected information to deepen the thinking of the topics rather than just remembering the whole details of the learning materials without consideration.

Ford\&Coffey refer that through the use of concept maps and icons that control modes of the output of information, users can navigate the knowledge and select information specific to the user's needs [7]. After they complete the concept map, they are able to review the lesson and retrieve the information they want from concept maps.

According to Cho\&Kim, a concept map is valid, reliable, practical as an assessment tool [8]. Students explore the new information with the provided links in the process. Then, teachers can get feedback from the completed concept maps. Analysis of the pattern of concepts and links within the maps can be used to show students' understanding and mastery of various causal relationships.

The approach to concept map scoring in the study represents a distinct departure from traditional methods that focus on characteristics such as hierarchy and branching [9]. Traditional tests always focus on the result of the learning, which may not expose such developmental thought processes. However, doing the concept map assignment shows more comprehensive learning precess and their final achievements when students are doing the concept map assignment.

\section{METHODS}

We wanted to explore the impacts of using Nearpod as an interactive tool to teach in the project. We were also interested in how students responded to the lesson through activities compared to traditional teaching methods. In the Nearpod lessons, when students were completing the questions, we could measure their performances by quizzes and collaborate boards.

We designed the lesson on the Nearpod, integrating information on global warming with different technologies on the platform. The students participating in the study were 11 th grade.

First, we chose the learning content, which included an introduction, effects of global warming and their causes. Then, we designed an appropriate teaching method to present the prepared content scientifically and acceptably in Nearpod. We made good use of Nearpod by integrating various high cognitive tasks into the lesson. A YouTube video was selected to raise students' interest and alert them to the situation nowadays; then, they would share their opinions on the collaborative board with their peers. The project included active learning methods (e.g., multiple choice polls and quizzes) where students completed class activities as their feedback regarding their understandings of the class. The platform could render the information as well as enhance students' self-regulated learning abilities.

Then, students submitted the answers, and the responses were presented on charts, so teachers knew how much they had explored and understood. When students were learning the effects of global warming, we did not give students the information or web content directly, which was simply an information transformation work. We created a concept map 
assignment, providing them links to explore the websites with group members. Therefore, students could learn the contents by themselves and connect one new information with others to form an interconnected map.

This qualitative research takes one class as an example to see how Nearpod can be designed as an interactive tool in class.

We designed those activities after each part, and students answered questions like matching pairs to see whether they have remembered the knowledge of the effects of global warming. There were also some openended questions to show their understanding of the learning information. When students completed the questions, teachers could analyze the data and see if the Nearpod worked.

This study was designed for 11th-grade students.30 students and three teachers participated in the study. To meet the linguistic problems and make the lesson more high-cognitive, teachers needed to find creative and meaningful approaches to use the Nearpod as the platform, allowing students to communicate and work in groups through poll questions, quizzes and other activities.

\section{RESULTS}

\subsection{Concept Map}

We design the concept map assignment as an approach to learning the effects of global warming. Students can access websites using the links provided in the concept map and then collaboratively discuss with their group members. Students are supposed to complete the concept map with the phenomenon of each event, its causes and effects. Also, a concept map enables links between relevant concepts and their relationships with others.

Using concept maps in the class internalizes information with visual materials and enables students to build new knowledge from active engagement. It allows efficient learning and integration with information stored in memory [10], which enhances the mastery of information, promotes deeper understanding and thinking and expands knowledge with technological skills.

As a high-cognitive technology tool, a concept map is not used to facilitate and reinforce knowledge given in the courses but to assist students in arranging, searching, and representing their understanding of the topics. Concept questions are questions posed to students to encourage higher-order thinking and help them understand basic principles [11].

Concept maps begin with several given topics and then divide into specific topics. In class, it increases students' motivation, help them clarify and search the detailed information and relationships, and develops engagement to collaborate actively in the discussion. Also, we use a concept map as a methodology to teach and evaluate critical thinking [12].

We find that a concept map is a learning tool to improve students' comprehension and overview of the whole topic, which is also a feedback tool to reflect how much they explore.

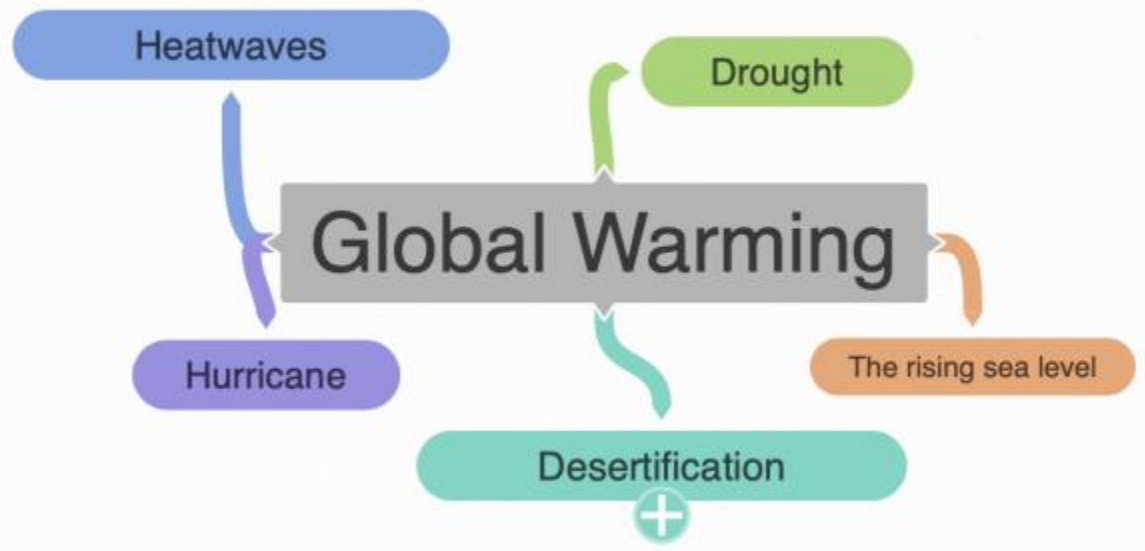

Figure 1. Concept map

\subsection{Collaborate Board}

According to Professor Hattie, feedback is the most powerful single modification that enhances achievement, and it is the simplest prescription for improving education [13]. Based on this, we provide the following
"Web Content" about the 5 main causes for global warming, which students would together discuss with their partners and explain how their assigned topic contributes to global warming as a whole in their own words later on the "Collaborate Board", where opinions are exposed and exchanged. Therefore the feedbacks from peers are highly welcome. 


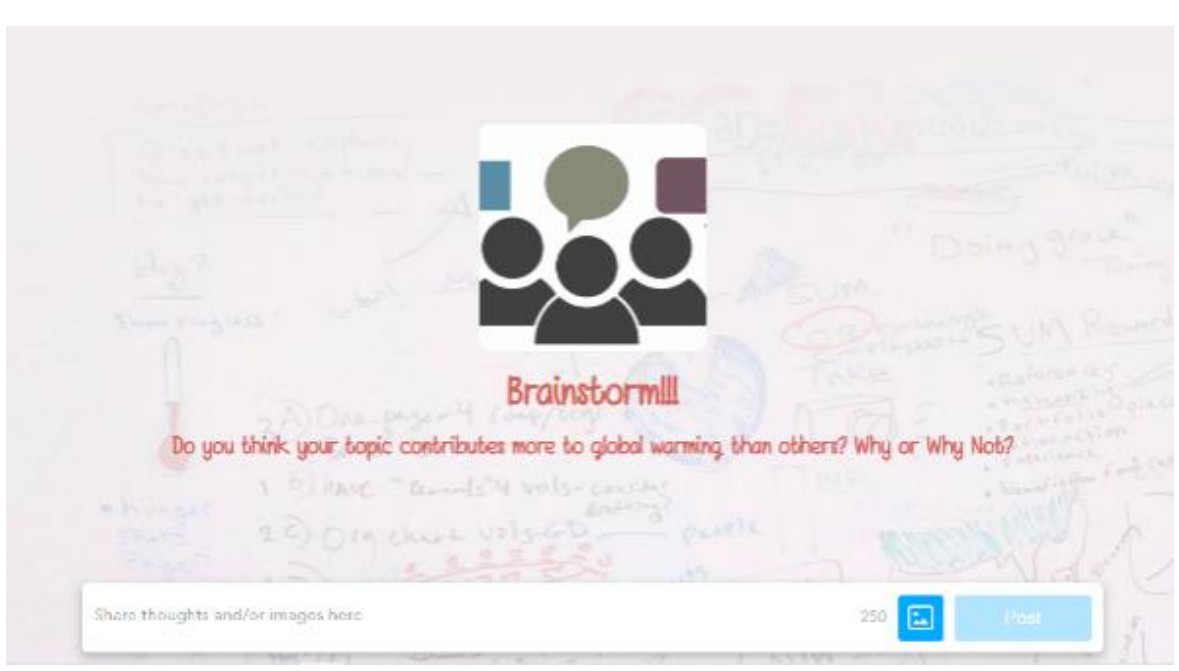

Figure 2. Collaborate Board

On the "Collaborate Board" above, we expect students to have a discussion or "debate" on the 5 different causes they are assigned that contributes to global warming, which is "Variations in the Sun's Intensity", "Industrial Activity", "Agricultural Activity", "Deforestation", "Earth's Own Feedback Loop". For example, here below could be one of the possible conversations between students:

SA (Student A): Don't you guys think that it's actually deforestation that plays the most important role? You know how many trees are cut down every time we blink our eyes? It's horrible, and I think we should really focus on Forest Protection the most when fighting global warming.

SB (Student B): Emm...I guess so...? But I'm afraid it's not the trees' problem. I mean, we ain't gonna solve this problem unless we kinda really put some efforts into reducing industrial activities. 'Cause we literally release too much greenhouse gasses into the atmosphere, and only planting trees won't necessarily help...

SC (Students C): Excuse my interruption, but I just want to remind you guys that we are actually living on one of the planets in the solar system, which means our environment is greatly influenced by the Sun! Could it be the variations in the Sun's intensity the biggest part of this problem then?

Through the conversations above, students can learn better not only how their own assigned topic is affecting global warming but also others. Provided with opinions and feedback, they can be very likely to have a better and deeper understanding of most if not all the causes of global warming, especially how they work in various ways. Thus, we believe that they could be well prepared to come up with ideas for later solving the tricky environment problem.

Generally, we made fairly good use of Nearpod by integrating such high cognitive tasks into the lesson.
Before the "official start" of the course, we introduce a short film from YouTube to get students alerted to the serious situation of global warming, and they will share their opinions on it later on the "Collaborate Board" with their peers. We cannot wait to see them posting, "Indeed, this is kinda creepy. I think we should do something about it." Or it could be a relevant picture they want to share, or they could also ask something like, "I like this video, but what is that sentence supposed to mean in 2:56?"

Additionally, we use several assessments to trace students' learning status during the whole course. "Collaborate board" also work as a tool to benefit students as a formative assessment. Students are free to write down anything they still have questions about. This process motivates students to review all the contents in the lesson and could provide accurate feedback for teachers.

\subsection{Formative Assessment}

At last, we use summative assessment to provide evidence for students' achievements [14]. Students can exchange their opinions with each other about what they have learnt in the lesson. During the process, teachers could know different students' situations about the class. In this way, teachers could analyse individuals from their own feedback about their learning and measure the understanding of the lesson from their group concept map. Also, according to the research reported by Dylan William, Professor Emeritus of Education, and Paul Black, Professor Emeritus of Education, the formative assessment does improve learning [15].

\section{DISCUSSION}

We compared two kinds of normal ways teachers use in education. In most traditional ways, students having classes without any electronic devices. In this way, the only students can preview the theme by reading the 
papers teachers provide for them. This may help students contribute a standard impression of the theme. But when everybody read the same material, their ideas must be very similar and less ingenious. When they do final projects, their work may be very similar to each other's. During the class, it was only the teacher on the stage to talk about the theme. Instead, using Nearpod or other electronic devices could provide various ways for students to get information. Thus, different students could get different ideas about the same since their researches were in different ways. Last, students need to do some quizzes on paper, and teachers need to correct their answers by hand in the traditional way. However, with the use of Nearpod, students just need to click the mouse and choose their answers to the question on the screen. When the class ended, teachers could receive the quiz reports immediately and see the visual graph about the overall or even individual performances. In the whole process, Nearpod plays an important role because it could provide border range of information and form academic reports for teachers at one time.

Below, we summarize some shortcut keys for the template in three steps and compare the differences between innovation class and traditional classes: preparing for the class, during and after the class. When preparing for the class, the innovation class searches global warming online without any limitations and readings, when the traditional class does some readings about global warming and thinking about the theme of their teamwork. In the second step of during the class, innovation class teachers use Nearpod with several functions like 'content' introduce global warming for students, and then use 'matching pairs' and 'quiz' to evaluate their learning performance. After that, the teacher could demonstrate the concept map for students and provide an example for them to refer to, whereas traditional class teachers just use some pictures or videos to show them what global warming is and teach them how to use a concept map for their teamwork. In the third step of "after the class," students search online and combine with the sample teacher provided to finish their teamwork. At the same time, it is very convenient for teachers to evaluate students' performance because nearpod has accounted for the data. Still, in a traditional class, they need to research by themselves and filter various information for their project. Additionally, they need to write some paper about what they have learnt today for teachers to evaluate their performances.

\section{CONCLUSION}

The most important advantage of Nearpod is that it could provide various perspectives to introduce students to the theme. When preparing the class, students could search by themselves about the theme and kindle their ideas about the final project. During the class, the most important process is that teachers could use Nearpod to bring students into the theme such as Global Warming. Compared with the traditional teaching method by using PowerPoints, Nearpod has more functions for teachers to complete the whole class. They could use videos or web content to introduce various information to lay the foundation for them. Then, students were asked to do their final project on the concept map. This software shows relationships between different kinds of causes and effects in visual. It needs students to clarify the differences between different terms clearly. At last, students need to do a quiz or matching pairs in different levels so that teachers can know the overall performances of the class in visual because the software has made the graph about the test. The concept map scoring method in the research is completely different from the traditional method that focuses on features such as hierarchical structure and branching. Using electronic equipment to teach is a promising way in the future, and these software provide good plate forms to improve the quality of the class.

\section{REFERENCES}

[1] Nearpod. \&lt;www.nearpod.com>. (2021). Retrieved 11 September 2021, from https://schlr.cnki.net/zn/Detail/index/WWMERGEJ LAST/SJPM3F0BA7F82DCE79BACBB7D1E528 AF8716

[2] Lowrybrock, M. R. . (2016). The effect of using Nearpod as a tool of active learning in the high school science classroom.

[3]Slavin, R. E. (1995). An introduction to cooperative learning. In cooperation learning:Theory, research, and practice (2nded., pp.13).

[4]Black, P., \& Wiliam, D. (2009). Developing the theory of formative assessment.Educational Assessment, Evaluation \& Accountability, 21(1), 31.

[5] Kinchin, Ian, M. , Hay, \& David, B. . (2000).

How a qualitative approach to concept map analysis can be used to aid learning by illustrating. Educational Research.

[6] Stensvold, M. S. , \& Wilson, J. T. . (1990). The interaction of verbal ability with concept mapping in learning from a chemistry laboratory activity. Science Education, 74(4), 473-480.

[7] Ford, K. M. , Canas, A. J. , \& Coffey, J. W. . (1996). Concept mapbased multimedia computer system for facilitating user understanding of a domain of knowledge. US, US5506937 A.

[8] Cho, J. I. , \& Kim, J. (2002). A study on validity, reliability and practicality of a concept map as an assessment tool of biology concept understandings. 
Journal of The Korean Association For Science Education, 22(2).

[9]Rice, D. C., Ryan, J. M., \& Samson, S. M. (1998). Using concept maps to assess student learning in the science classroom: Must different methods compete?. Journal of Research in Science Teaching: The Official Journal of the National Association for Research in Science Teaching, 35(10), 1103-1127.

[10]Martin D.(2011). Concept mapping, mind. mapping and argument mapping: what are the differences and do they matter?Higher Education, Vol. 62, No. 3 (September 2011), pp. 279-301

[11] Darmofal, D. L. , Soderholm, D. H. , \& Brodeur, D. R. . (2002). Using concept maps and concept questions to enhance conceptual understanding. Frontiers in Education, 2002. FIE 2002. 32nd Annual. IEEE.

[12] Daley, B. J. , Shaw, C. R. , Balistrieri, T. , Glasenapp, K. , \& Piacentine, L. . (1999). Concept maps: a strategy to teach and evaluate critical thinking. Journal of Nursing Education, 38(1), 4247.

[13]Hattie, J., \& Timperley, H. (2007). The power of. feedback. Review of Educational Research, 77(1), 81-112.

[14] Black, P., \& William, D. (2009). Developing the. theory of formative assessment. Educational Assessment, Evaluation \& Accountability, 21(1), 31.

[15] Black, P.J. \& William, D. (2010) Inside the black box: Raising standards through classroom assessment. PhiDelta Kappan, 92(1), 81-90 